\title{
Effect of some medicinal plant extracts on multidrug resistant Helicobacter pylori strains isolated from Sohag and Assiut University Hospitals and some medical laboratories
}

\author{
${ }^{1}$ Magdy Abu-Gharbia, ${ }^{2}$ Michael N. Agban, ${ }^{3}$ Ayman M.A. Hamouda, ${ }^{4}$ Rasha Z. Abdelmasieh* \\ ${ }^{1}$ Botany Department, Faculty of Science, Sohag University \\ ${ }^{2}$ Medical Microbiology and Immunology Department, Faculty of Medicine, Assiut University \\ ${ }^{3}$ Medicinal and Aromatic Plants Department, Director of Horticulture Research Institute, Agriculture Research Center, Giza \\ ${ }^{4}$ Researcher in Medicinal and Aromatic Plants Department, Horticulture Research Institute, Agriculture Research Center, Giza
}

Key words:

Helicobacter pylori, class I carcinogen, antimicrobial Resistance, Medicinal plant extracts

*Corresponding Author: Rasha Zaher Abdelmasieh Researcher in Medicinal and aromatic plants department,

Horticulture research institute Agriculture research center,

Giza

Tel.: 01225100285

rzaher094@gmail.com
ABSTRACT

Background: Helicobacter pylori is a micro-aerophilic Gram-negative bacteria. The increasing resistance between strains was emerged, resistance to such antimicrobial agents continues to be alarming worldwide. Objectives: to isolation of $H$. pylori by bacterial culture and evaluate the resistance rate of bacteria to antimicrobials and effect of medicinal plant extracts (A. sativum and C. carvi essential oil, Moringa oleifera, Trigonella foneum, Lawsonia inermis) on $H$. pylori strains and detection of their effective components.. Methodology: This study was done on stool samples collected from 260 patients attending gastroenterology department at Sohag and Assiut University Hospital, collected during the period from March 2019 to February 2020. The bacterial cultures were done for isolation of the pathogenic bacteria and detection of their antibiotic susceptibility by disc diffusion method and Minimum inhibitory concentration (MICs) determination and treatment of resistant strains with medicinal plant extracts as natural products and detection of their active constituents qualitatively and quantitatively. Results: $87.0 \%$ and $59.2 \%$ sensitive strains of $H$. pylori to A. sativum and C. carvi essential oil and $67.4 \%, 57.1 \%, 44.9 \%$ susceptible strains to T. foneum gracium, M. oleifera, L. inermis were detected. Flavonoids, alkaloids, tannins, phenols as phytochemicals were detected in Moringa oleifera, Trigonella foneum, Lawsonia inermis methanolic extracts causing their antibacterial activity. Disulfide diallyl (30.12\%) and limonene (46.39\%) and carvone (50.30\%) were as bioactive compounds in Allium sativum and Carium carvi essential oil. Conclusion: results, we concluded that the medicinal plant extracts were the most effective agents as antimicrobials so we recommend the use of these extracts as alternatives in the future to treat the resistance problem.

\section{INTRODUCTION}

Helicobacter pylori is a micro-aerophilic Gramnegative spiral bacterium ${ }^{1}$. It is related to chronic gastritis, gastric ulcers, duodenal ulcers and stomach mucosal atrophy ${ }^{2}$. Moreover, Helicobacter pylori is well recognized as a class I carcinogen because $H$. pylori is believed to be closely involved in the chronic inflammation behind duodenal ulcers and gastric diseases, and therefore it is crucial to understand how $H$. pylori causes the progression from acute inflammation of the mucosa to gastric cancer. ${ }^{3}$

Resistance of $\mathrm{H}$. pylori to such antimicrobial agents ${ }^{4,5}$ continues to be alarming worldwide. The increased prevalence of resistance of $\mathrm{H}$. pylori resulting from the extensive use of antibiotics may render the insufficient current antimicrobial agents to control at least some bacterial infections ${ }^{6}$. So the search for effective and safe medicines used to treat particularly persistent bacterial infections is continuous ${ }^{7}$ and the scientists are now paying attention towards natural products such as herbal extracts or medicinal plant extracts to represent as microbial agents ${ }^{8}$

Medicinal plant is an important part of indigenous medical systems in all over the world. The ethnobotany considers a substantial resource for research and development of natural drug. Natural products have a great role throughout the world in treatment and prevention of human diseases. The importance of natural products in this field can be resulted from: the presence of new chemical entities of wide diversity of structural natural substances serving as templates for 
semi synthetic and total synthetic modification, these chemical substances are active to a number of diseases, and increased use of these substances in the treatment of disease. ${ }^{9}$, The broad and complex activity of essential oils, as well as their synergy of action, can make them essential oil as one of natural products is a valued weapon against multidrug resistant bacterial strains due to its broad and complex activity and strong action. After using essential oil as anti-bacterial, there is no evidence of emergence of resistant bacteria after their usage, and this is highly hopeful in the treatment of human diseases in future $10,11,12,13$

Efforts and trails toward the collected baseline data on medicinal plants, phytochemical and pharmacological studies and innovation are very confined for future. Many scientists have concentrated the essential need for discovering new, safe, and cheap antibiotics with diverse chemical structures, new chemical actions, and no adverse side effects because of the indiscriminate use of antibiotics increasing emergence of resistant microbial strains. The presence of bioactive constituents in the medicinal plants render these plants are important candidates for future researchable studies in future including pharmacological studies and drug discovery. ${ }^{14}$

The aim of the present study is to evaluate antibiotic susceptibility of $H$. pylori and the ability of medicinal plant extracts to inhibit the resistant strains because these medicinal plants may be used in the pharmaceutical industry (as alternatives) in future without the side effect.

\section{METHODOLOGY}

\section{Bacterial culture:}

For $H$. pylori culture, 260 stool specimens were collected from patients of Sohag and Assiut University Hospitals (Gastroenterology Department) and some medical laboratories. A homogenized sample in saline solution or buffer was inoculated onto blood agar base plate supplemented with campylobacter supplement-III (Skirrow). The plates were incubated for up to 7 days at $37^{\circ} \mathrm{C}$ under micro-aerophilic conditions $\left(10 \% \mathrm{O}_{2}, 5 \%\right.$ $\mathrm{CO}_{2}$, and $85 \% \mathrm{~N}_{2}$ ). H. pylori isolates were identified based on colony morphology; Gram staining results and positive biochemical tests (reactions of oxidase, catalase and urease).

Antimicrobial susceptibility test by disc diffusion method:

210 isolates of $H$. pylori were tested against ten antibiotics. $H$. pylori inoculum was prepared $\left(1.5 \times 10^{8} \mathrm{CFU} / \mathrm{ml}\right.$ equivalent to 0.5 McFarland), inoculated on Müeller Hinton agar supplemented with $5 \%$ to $10 \%$ horse blood, selected different antibiotics discs (tetracycline $(30 \mu \mathrm{g})$, clarithromycin $(15 \mu \mathrm{g})$, ciprofloxacin $(5 \mu \mathrm{g})$, levofloxacin $(5 \mu \mathrm{g})$, amoxicillin $(10 \mu \mathrm{g}), \quad$ rifampin $(5 \mu \mathrm{g}), \quad$ gentamicin $\quad(10 \mu \mathrm{g})$, erythromycin $(10 \mu \mathrm{g})$, furazolidone $(30 \mu \mathrm{g})$ and metronidazole $(5 \mu \mathrm{g})$ ) were placed on the inoculated media. The plates were incubated for 72 hours at $37^{\circ} \mathrm{C}$ in micro-aerophilic atmosphere $\left(5 \% \mathrm{O}_{2}, 10 \% \mathrm{CO}_{2}\right.$, and $85 \% \mathrm{~N}_{2}$ with $100 \%$ humidity).We selected $49 \mathrm{H}$. pylori strains as multidrug resistant for testing the plant extracts effect.

\section{The extraction method:}

Finely ground sample (seeds of fenugreek or leaves of moringa or henna leaves) was extracted using the Soxhelt apparatus with the methanol by steam distillation method. The garlic and caraway essential oil were extracted through the performance of hydrodistillation process of the grounded garlic or caraway using a Clevenger-type apparatus. ${ }^{15}$

\section{Antimicrobial activity measurements: \\ Disk diffusion method:}

Forty nine drugs resistant strains (selected as more multi drug resistant strains) were tested against the medicinal extracts. An inoculum was prepared $\left(1.5 \times 10^{8} \mathrm{CFU} / \mathrm{ml}\right.$ equivalent to $0.5 \mathrm{McF}$ arland), placed on Müller-Hinton agar supplemented with $10 \%$ horse serum, and then different plant extracts in volume of 10 $\mu \mathrm{l}$ were applied on the discs. Antibiotics were used as positive control and DMSO as negative control. Media plates were incubated at $37^{\circ} \mathrm{C}$ for 3 days. All plates were examined for zones of inhibition. The diameters of the inhibition zones were measured in millimeters (mm).

\section{Minimum inhibitory concentration (MICs) determination:}

By two fold serial dilution method, each extract stock (1000 ppm or $1000 \mathrm{mg} / \mathrm{ml}$ ) was prepared by dilution in distilled water from 1000 to $31.2 \mathrm{mg} / \mathrm{ml}$ $(31.2,62.5,125,250,500$ and $1000 \mathrm{mg} / \mathrm{ml})$ and essential oil $(1 \mathrm{v})$ from 1 to $1: 16(1,1: 1 / 2,1: 1 / 4,1: 1 / 8$, $1: 1 / 16,1: 1 / 32 \mathrm{v} / \mathrm{v})$. Sterile filter paper discs of $6 \mathrm{~mm}$ diameter were impregnated in $20 \mu \mathrm{L}$ of each concentration of plant extract solution and essential oil, the disks were softly put on the agar. Distilled water was considered as negative control. Plates were incubated at $37^{\circ} \mathrm{C}$ in micro-aerophilic conditions for 3 5 days. The diameters of inhibition zones were measured.

\section{Qualitative phytochemical analysis:}

Phytochemical analysis of methanolic extract of selected medicinal plants was carried out by the standard methods for detection of presence or absence of metabolites such as alkaloids, flavonoids, phenol, saponine, steroids and tannins.

\section{Quantitative phytochemical analysis:}

Chemical tests were done to the methanolic extract of selected three medicinal plants using standard procedure to identify the constituents such as total flavonoids, total phenolics and total tannins. 
Gas chromatography-Mass spectrometry (GC-MS) analysis:

The gas chromatographic analysis was carried out for essential oil of Allium sativum and Carium carvi using DsChrom 6200 Gas Chromatograph equipped with a flame ionization detector for separation of volatile oil constituents.

\section{RESULTS}

Table 1: Susceptibility pattern of $H$. pylori strains to different antibiotics:

\begin{tabular}{|c|c|c|c|c|}
\hline antibiotics & Sensitive no & Resistant no & Sensitivity rate \% & Resistance rate \% \\
\hline AMX & 37 & 12 & 75.5 & 24.5 \\
\hline CRP & 33 & 16 & 67.3 & 32.7 \\
\hline ER & 5 & 44 & 10.2 & 89.8 \\
\hline FURA & 11 & 38 & 22.4 & 77.6 \\
\hline GN & 5 & 44 & 40.2 & 59.8 \\
\hline LVX & 24 & 25 & 49.0 & 98.0 \\
\hline MNZ & 1 & 48 & 6.0 & 93.9 \\
\hline TCN & 3 & 46 & 26.5 & 73.5 \\
\hline CAM & 13 & 36 & 14.3 & 85.7 \\
\hline
\end{tabular}

From 260 stool samples, 210 samples were positive culture to H. pylori. The antimicrobial susceptibility testing was carried out. Forty nine strains were multidrug resistant to antibiotics as in (Table 1, Fig1)

Table 2):Sensitivity and resistance rates of multi-drug resistant strains of $\mathrm{H}$. pylori to medicinal extracts of some plants by disk diffusion method:

\begin{tabular}{|c|c|c|c|c|c|}
\hline & \multicolumn{2}{|c|}{ Essential oil } & \multicolumn{3}{c|}{ Methanolic extract } \\
\cline { 2 - 6 } & A. sativum & C. carvi & M. oleifera & T. foneum gracium & L. inermis \\
\hline Sensitivity rate & $43(87.7 \%)$ & $29(59.2 \%)$ & $28(57.1 \%)$ & $33(67.4 \%)$ & $22(44.9 \%)$ \\
\hline Resistance rate & $6(12.2 \%)$ & $20(40.8 \%)$ & $21(42.9 \%)$ & $16(32.6 \%)$ & $27(55.1 \%)$ \\
\hline
\end{tabular}

The resistant strains were treated to medicinal plant extracts by disc diffusion method, these strains were highly sensitive to A. sativum essential oil $87.7 \%$ and T. foneum gracium methanolic extract $67.4 \%$. (table 2)

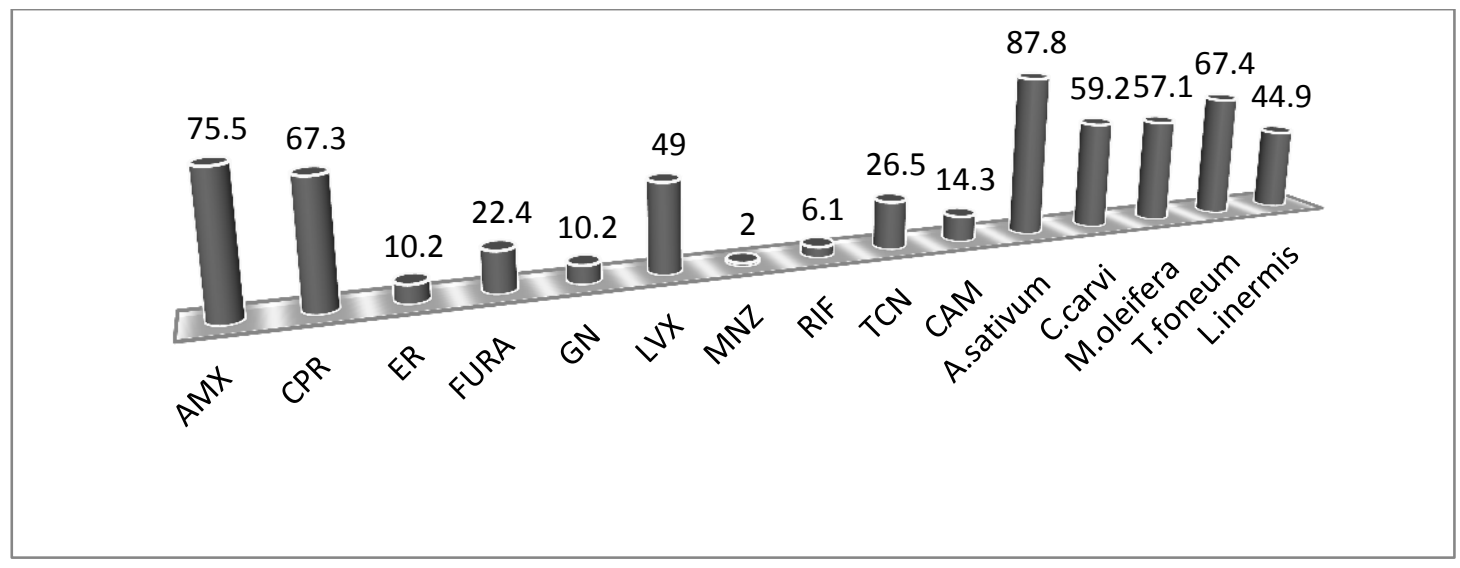

Fig. 1: Sensitivity rate of H. pylori strains to antimicrobials and plant extracts 


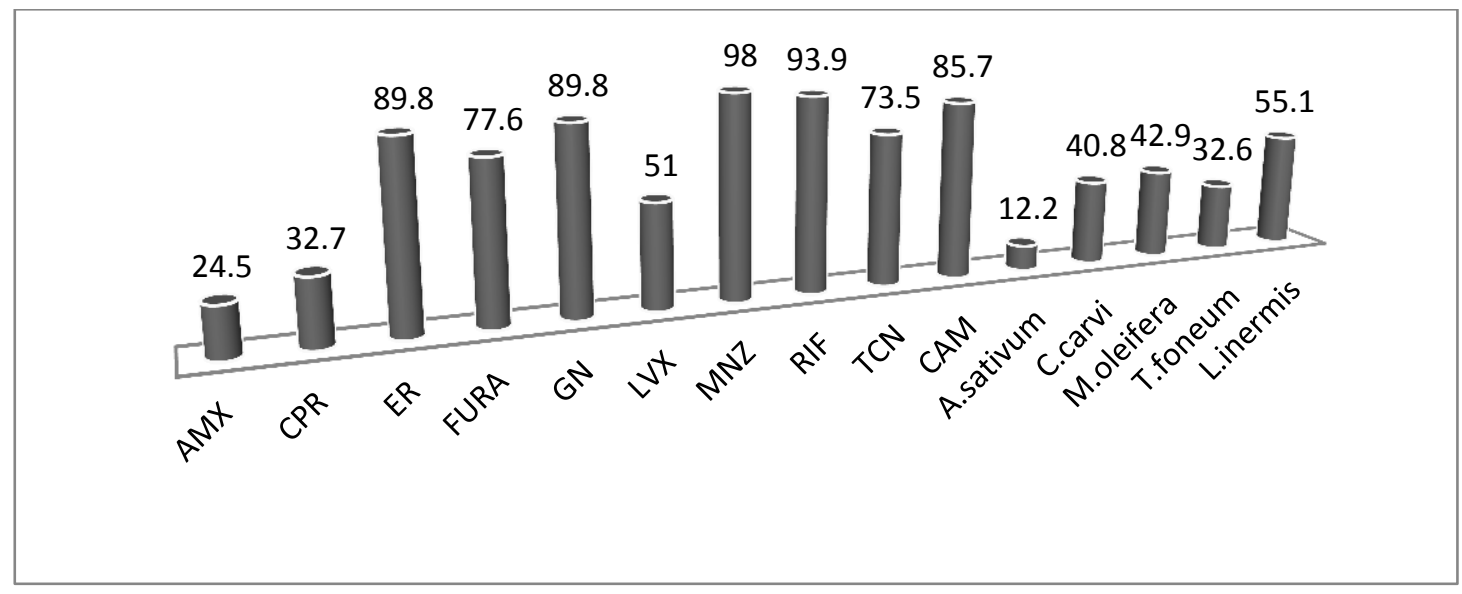

Fig. 2: Resistance rate of H. pylori strains to antimicrobials and plant extracts

Comparison between sensitivity rate of $\mathrm{H}$. pylori to antibiotics and medicinal plant extracts cleared higher sensitivity rate to natural extracts than antibiotics. (Fig 1,2)

Table 3: MICs of methanolic extracts of M. oleifera, T. foneum gracium and L. inermis and A. sativum and $C$. carvi essential oil against selective multidrug resistant $H$. pylori strains

\begin{tabular}{|c|c|c|c|c|c|c|c|c|c|c|c|}
\hline \multicolumn{5}{|c|}{ Essential oil } & \multicolumn{7}{|c|}{ Methanolic extract } \\
\hline & \multicolumn{2}{|c|}{ A. sativum } & \multicolumn{2}{|c|}{ C. carvi } & & \multicolumn{2}{|c|}{ M. oleifera } & \multicolumn{2}{|c|}{$\begin{array}{c}\text { T. foneum } \\
\text { gracium }\end{array}$} & \multicolumn{2}{|c|}{ L. inermis } \\
\hline MIC & $\begin{array}{c}\text { No. } \\
\text { inhibited } \\
\text { strains }\end{array}$ & $\%$ & $\begin{array}{c}\text { No. } \\
\text { inhibited } \\
\text { strains }\end{array}$ & $\%$ & Dilutions & $\begin{array}{c}\text { No. } \\
\text { inhibited } \\
\text { strains }\end{array}$ & $\%$ & $\begin{array}{c}\text { No. } \\
\text { inhibited } \\
\text { strains }\end{array}$ & $\%$ & $\begin{array}{c}\text { No. } \\
\text { inhibited } \\
\text { strains }\end{array}$ & $\%$ \\
\hline $1: 2$ & 0.0 & $0.0 \%$ & 5.0 & $10.2 \%$ & 500 & $2.0 \%$ & 1.0 & $0.0 \%$ & 0.0 & $12.2 \%$ & 6.0 \\
\hline $1: 4$ & 9.0 & $18.4 \%$ & 8.0 & $16.3 \%$ & 250 & $12.2 \%$ & 6.0 & $28.6 \%$ & 14.0 & $4.1 \%$ & 2.0 \\
\hline $1: 8$ & 10.0 & $20.4 \%$ & 6.0 & $12.2 \%$ & 125 & $26.5 \%$ & 13.0 & $14.3 \%$ & 7.0 & $0.0 \%$ & 0.0 \\
\hline $1: 16$ & 5.0 & $10.2 \%$ & 6.0 & $12.2 \%$ & 62.5 & $16.3 \%$ & 8.0 & $14.3 \%$ & 7.0 & $0.0 \%$ & 0.0 \\
\hline $1: 32$ & 15.0 & $30.6 \%$ & 0.0 & $0.0 \%$ & 31.2 & $0.0 \%$ & 0.0 & $0.0 \%$ & 0.0 & $0.0 \%$ & 0.0 \\
\hline $1: 64$ & 3.0 & $6.1 \%$ & 0.0 & $0.0 \%$ & & & & & & & \\
\hline
\end{tabular}

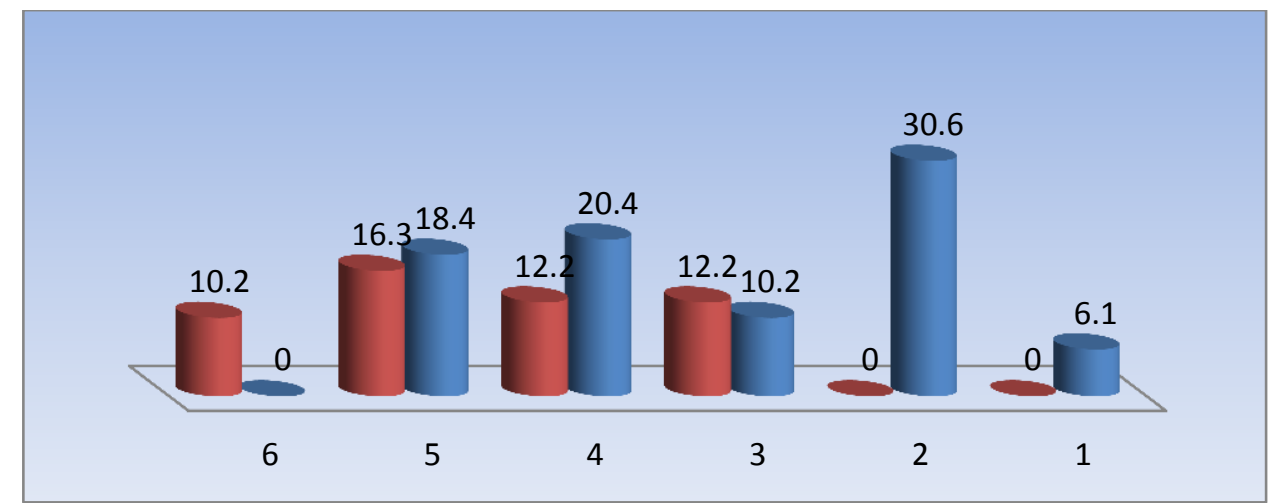

Fig. 3: The determination of MIC of essential oil of A.sativum\& C.carvi inhibiting selective multidrug resistant $H$. pylori strains isolated from patients of Soagh + Assiut hospital university and some medical labs 


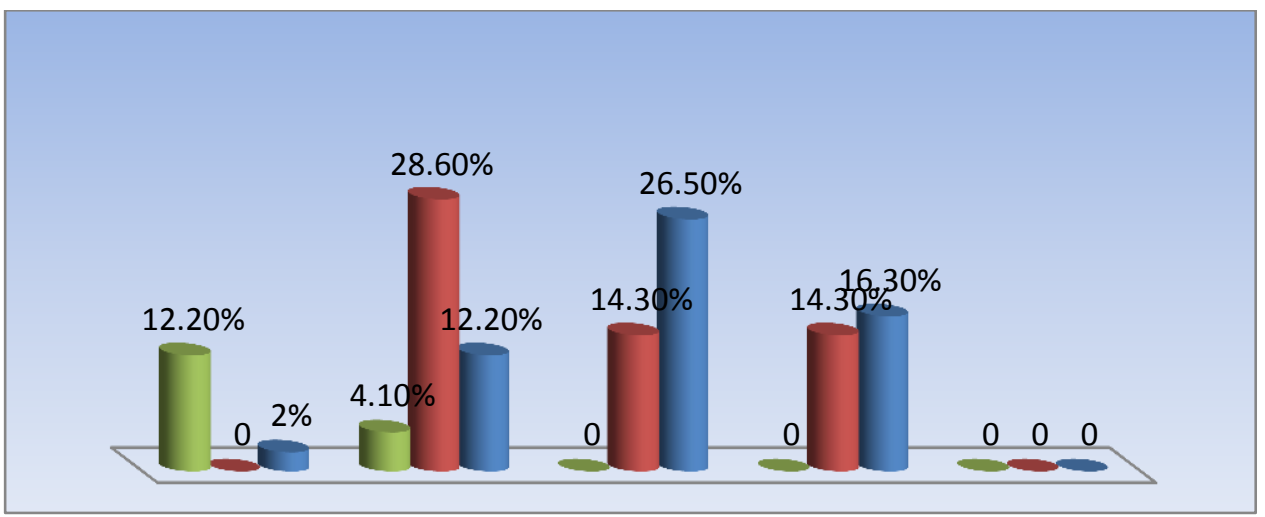

Fig. 4: MICsof methanolic extracts of M. oleifera, T. foneum gracium and $L$. inermis against selective multidrug resistant $H$. pylori strains isolated from patients of Sohag + Assiut hospital univeristy some medical labs

The antimicrobial activities of essential oil and extracts were determined by the determination of minimum inhibitory concentration (MICs).87.7\% and $59.2 \%$ of $H$. pylori strains were sensitive to A. sativum and $C$. carvi essential oil respectively while $67.4 \%$, $57.1 \%, 44.9 \%$ of $H$. pylori strains were susceptible to $T$. foneum gracium, M. oleifera, L. inermis. Essential oil of A. sativum and $C$. carvi showed strong antimicrobial activities with MIC $0.03125(1: 32)$ to $30.6 \%$ of strains and $0.25(1: 4)$ to $16.3 \%$ of strains so A. sativum had stronger antimicrobial activity than $C$. carvi. MIC of $\boldsymbol{M}$. oleifera and $\boldsymbol{T}$. foneum gracium extracts inhibited $26.5 \%$ and $28.6 \%$ of bacterial growth was $125 \mathrm{mg} / \mathrm{ml}$ and $250 \mathrm{mg} / \mathrm{ml}$ whereas MIC of $\boldsymbol{L}$. inermis extract inhibited $12.5 \%$ of bacterial growth was $500 \mathrm{mg} / \mathrm{ml}$. (Table3, Fig3,4)

Table 4: The preliminary screening of phytochemical components in methanolic extracts of $M$. oleifera, T. foneum gracium and $L$. inermis (the qualitative analysis)

\begin{tabular}{|c|c|c|c|}
\hline & M. oleifera & T. foneum gracium & L. inermis \\
\hline flavonoids & + & + & + \\
\hline Alkaloids & + & + & + \\
\hline Tannins & + & + & + \\
\hline Saponins & + & + & + \\
\hline Glycosides & + & + & + \\
\hline Terpenoids & + & + & + \\
\hline Phenols & + & + & + \\
\hline Steroids & + & + & + \\
\hline Carbohydrates (reducing sugar) & + & + & + \\
\hline
\end{tabular}

The methanolic extract of $T$. foneum gracium, L. inermis displayed the presence of some phytochemicals including flavonoids, alkaloids, tannins, saponins, glycosides, terpenoids, steroids, phenols, reducing sugar, proteins and aminoacids while $M$. oleifera showed the presence of almost all phytochemicals except reducing sugar (Table 4).

Table 5: Assessment of the total phenols, total flavonoids, tannins contents in methanolic extracts of $M$. oleifera, T. foneum gracium and $L$. inermis (the quantitative analysis)

\begin{tabular}{|c|c|c|c|}
\hline Constituents & Total phenols & Total flavonoids & Tannins \\
\hline Methanolic extract & & & $\mathbf{0 . 4 9}$ \\
\hline M. oleifera & $\mathbf{4 1 3 . 7 6}$ & $\mathbf{3 . 6 1 4}$ & $\mathbf{0 . 4 6}$ \\
\hline L. . inermis gracium & $\mathbf{5 4 3 . 3}$ & $\mathbf{5 . 5 3 1}$ & $\mathbf{2 . 6 7}$ \\
\hline
\end{tabular}

The quantification of the phytochemical constituents of these plant extracts revealed the variations in concentrations of alkaloids, flavonoids and tannins as shown in (Table 5). 
Table 6: The chemical components of Allium sativum and Carium carvi essential oil by GC-MS chromatogram analysis

\begin{tabular}{|c|c|c|}
\hline & Allium sativum & Area\% \\
\hline Component name & Retention Time & $\mathbf{1 . 1 7}$ \\
\hline dimethyl disulfide & $\mathbf{2 . 6 5}$ & $\mathbf{1 . 5 7}$ \\
\hline dimethyl sulfide & $\mathbf{2 . 8 7}$ & $\mathbf{1 . 7 2}$ \\
\hline allyl methyl disulfide & $\mathbf{3 . 6 9}$ & $\mathbf{3 0 . 1 2}$ \\
\hline diallyl disulfide & $\mathbf{5 . 3 4}$ & $\mathbf{1 2 . 3 4}$ \\
\hline allyl(Z)-1-propenyl disulfide & $\mathbf{5 . 8 0}$ & $\mathbf{5 . 1 1}$ \\
\hline allyl methyl trisulfide & $\mathbf{6 . 3 9}$ & $\mathbf{5 . 5 1}$ \\
\hline 2-vinyl-4-H-1,2 dithine & $\mathbf{7 . 8 7}$ & $\mathbf{2 2 . 6}$ \\
\hline diallyl trisulfide & $\mathbf{8 . 2 4}$ & $\mathbf{3 . 8 2}$ \\
\hline allyl propyl trisulfide & $\mathbf{8 . 6 0}$ & $\mathbf{7 . 0 2}$ \\
\hline diallyl tetrasulfide & $\mathbf{1 1 . 4 5}$ & $\mathbf{1 . 1 2}$ \\
\hline \multicolumn{3}{|c|}{ Carium carvi } \\
\hline myrcene & $\mathbf{3 . 0 4}$ & $\mathbf{4 6 . 3 9}$ \\
\hline limonene & $\mathbf{3 . 5 5}$ & $\mathbf{1 . 5 9}$ \\
\hline trans carveol & $\mathbf{7 . 9 4}$ & $\mathbf{5 0 . 3 0}$ \\
\hline carvone & $\mathbf{9 . 2 6}$ & $\mathbf{0 . 6 0}$ \\
\hline carveol & $\mathbf{9 . 8 8}$ &
\end{tabular}

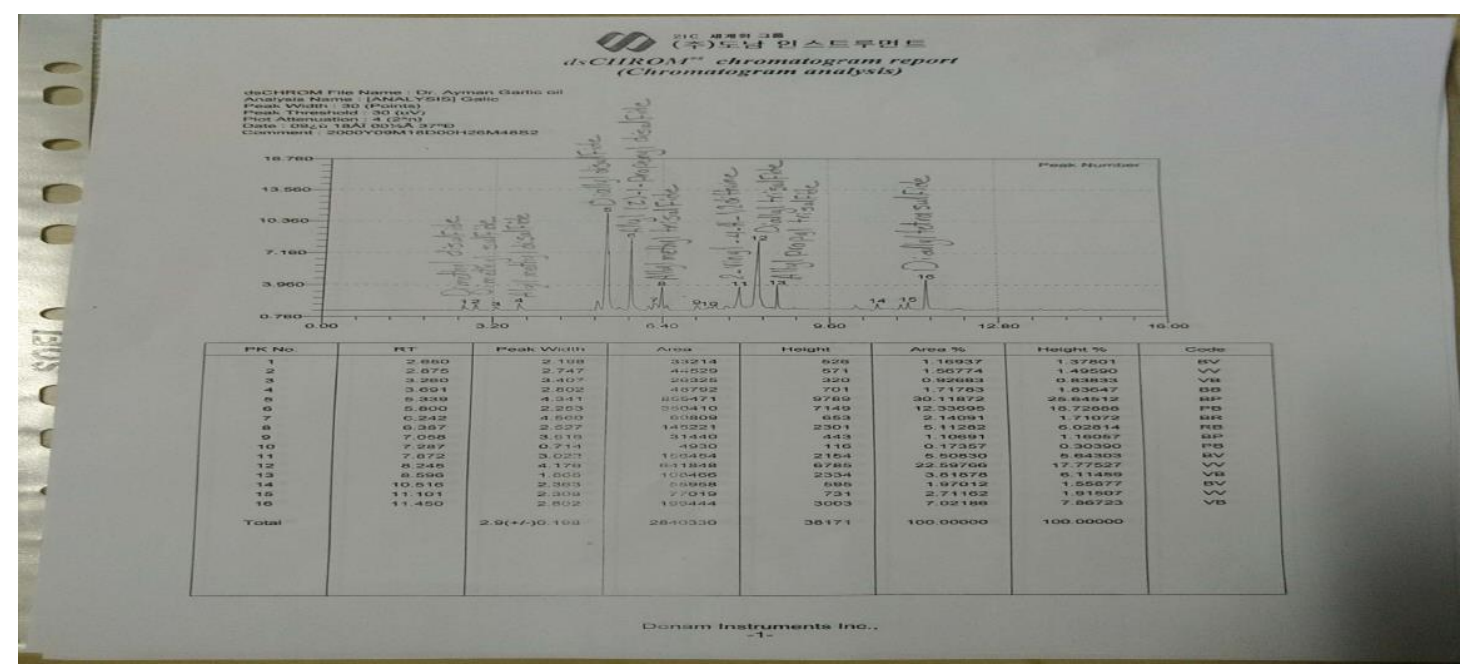

Fig. 5: GC-MS chromatogram analysis of Allium sativum essential oil

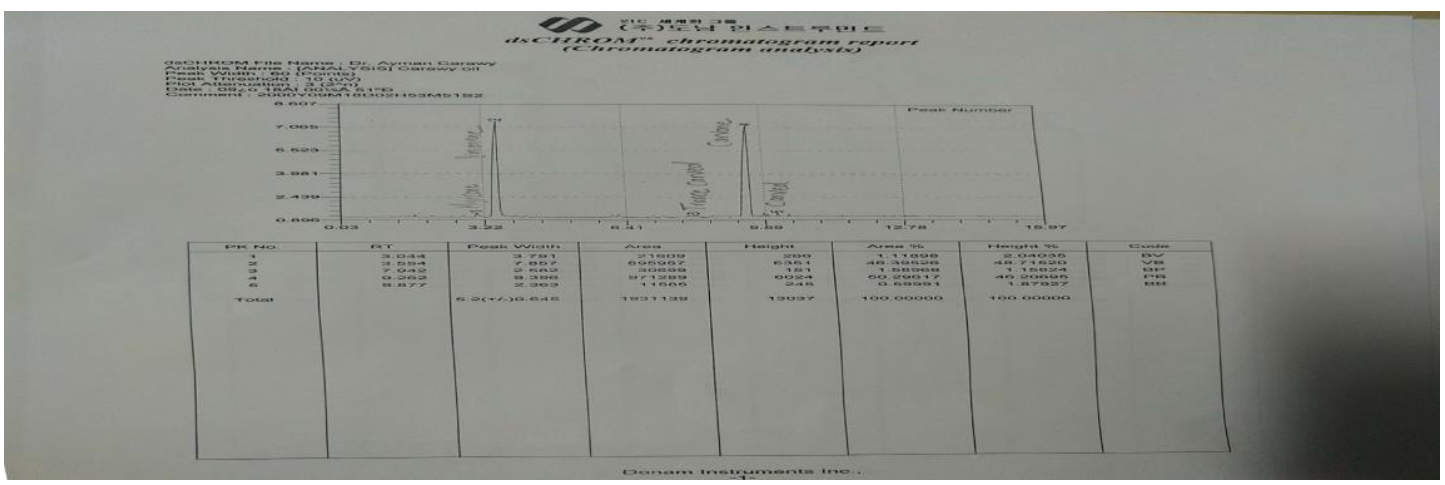

Fig. 6: GC-MS chromatogram analysis of Carum carvi essential oil

GC-MS chromatogram of A. sativum and C. carvi essential oil identified ten phytochemical compounds and five phytochemical compounds in C. carvi were based on the peak area, retention time and molecular formula (Table 6, Fig $5,6)$ 


\section{DISCUSSION}

H. pylori specifically settles the gastric epithelium and is the most prevalent human bacterial infection worldwide, infecting approximately half of the world's population $^{16,17}$.

All isolated H. pylori strains were described as rounded, small translucent and identified as Gramnegative and spiral shaped rods with rounded ends and positive oxidase, catalase, and urease, negative nitrite reduction, $\mathrm{H}_{2} \mathrm{~S}$ production and hippurate hydrolysis, these strains could not grow in the presence Nacl (3.5\%) and glycine (1\%), they were resistant to cephalothin and sensitive to nalidixic acid. Some of them could grow at $30,42^{\mathbf{0}} \mathrm{C}$ and others no. ${ }^{\mathbf{1 8}}$

Antibiotic resistance is a constantly evolving process and there are significant regional variations in $H$. pylori antibiotic resistance rates ${ }^{19}$. Numerous studies have been carried out to determine the prevalence of $H$ pylori resistance to antibiotics ${ }^{20}$

Antimicrobial susceptibility testing for Helicobacter pylori has highly magnitude due to increasing the resistance to the most used antimicrobials ${ }^{21}$ and increasing antibiotic resistance has minimized the efficacy of treatment regimens in recent years. ${ }^{\mathbf{2 2}}$.

Most common antibiotic-resistant strains of $H$. pylori are clarithromycin- and metronidazole-resistant, and they are present at very high rates but the rates vary among different populations. However, amoxicillin resistance is relatively low. The resistance of $H$. pylori to several antibiotics is widely varied widely between different geographical areas ${ }^{\mathbf{2 3}}$

In our study, the multidrug resistance was detected to rifampicin, metronidazole, gentamycin, tetracycline, furazolidone, erythromycin, tetracycline, levofloxacin and Clarithromycin. This was in agreement with the result of some previous studies that cleared the prevalent resistance to Clarithromycin, metronidazole, tetracycline $^{\mathbf{2 4 , 2 5}}$.

Amoxicillin followed by ciprofloxacin were the best antimicrobials for inhibiting $H$. pylori strains than others in this study, these data were similar to the study that reported high sensitivity to amoxicillin ${ }^{\mathbf{2 6}}$

Reduction of $H$. pylori antibiotic resistance is throughout evaluation of local antibiotic resistance and selection of appropriate first-line regimens ${ }^{27}$ that reduce repeated courses of treatment causing multiple side effects and propagation of secondary antibiotic resistance ${ }^{28}$. Because antibiotic resistance reflects its pattern of use in any geographical region so abuse of antibiotics increases resistance of $H$. pylori leading to more mutation in strains. ${ }^{29}$

The antibiotic resistance of bacteria is the leading reason of treatment failure ${ }^{30}$. Because of increasing resistance and treatment failure, bacterial infections relapse in most patients within a few years ${ }^{31}$ so There are the numerous studies concentrated on the eradication of $H$. pylori infection using traditional herbal medicines because the multi-drug resistance was developed ${ }^{32,33}$. The medicinal herbs is very effective to treat infections and have been used as alternatives (as drugs) to treat various diseases. ${ }^{\mathbf{3 4}, 35} \mathrm{~A}$. sativum had the strongest antibacterial activity against $H$. pylori strains than all the plant extracts in our study. Our study was consistent with some studies that had been emphasized on the existence of a relationship between consumption of garlic and decrease in Helicobacter pylori infection ${ }^{\mathbf{3 4}}$ and the other study that revealed the effectiveness of the garlic essential oil antibacterial properties on $H$. pylori.

Plant extracts contained variable active constituents. These compounds are known as secondary plant metabolites and have biological characteristics such as antioxidant activity, antimicrobial impact, modification of detoxification enzymes, activation of the immune system, and modification of hormone metabolism and anti-cancer property ${ }^{36}$

The antimicrobial effect of Allium sativum resulted from the presence of sulfur compounds either limonene and carvone in Carium carvi had inhibitory effect on gram positive and negative bacteria. ${ }^{37,38,39}$

\section{CONCLUSION}

From these results, we concluded that the medicinal plant extracts (as the natural products) were more effective agents than antimicrobials in addition to have no side effect. So we recommend the use of these extracts as alternatives in the future. This study also proved that Allium sativum extract was the most effective antimicrobial agent than other extracts and antimicrobials.

This study was approved by the ethical committee of Faculty of Science.

This manuscript has not been previously published and is not under consideration in the same or substantially similar form in any other reviewed media. I have contributed sufficiently to the project to be included as author. To the best of my knowledge, no conflict of interest, financial or others exist. All authors have participated in the concept and design, analysis, and interpretation of data, drafting and revising of the manuscript, and that they have approved the manuscript as submitted.

\section{REFERENCES}

1. Takahashi-Kanemitsu A, Christopher T. Knight, C.T, Hatakeyama, M. Molecular anatomy and pathogenic actions of Helicobacter pylori CagA that 
underpin gastric carcinogenesis. Cellular \& Molecular Immunol. 2020: 17; 50-63.

2. Shiota S, Thrift AP, Green L, Shah R, Verstovsek G, Rugge M, Graham DY, El-Serag HB. Clinical Manifestations of Helicobacter pylori-Negative Gastritis. Clin. Gastroenterol. Hepatol. 2017: 15; 1037-1046.

3. Piscione M, Mazzone M, Di Marcantonio MC, Muraro R, Mincione G. Eradication of Helicobacter pylori and gastric cancer: A Controversial relationship. Front. Microbiol. 2021: $12 ; 630852$.

4. Chopra I, Hawkey PM, Hinton M. Tetracyclines, molecular and clinical aspects. J. Antimicrob. Chemother. 1992: 29; 245-77.

5. Bhavani SM, Ballow CH. New agents for grampositive bacteria. Current opinion in Microbiol. 2000: 3; 528-534.

6. Babu, P.D. and Subhasree, R.S. Antimicrobial Activities of Lawsonia inermis - A Review. Academic J. Plant Sci. 2009: 2 (4); 231-232.

7. Sienkiewicz M, Łysakowska M, Denys P, Kowalczyk E. The antimicrobial activity of thyme essential oil against multidrug resistant clinical bacterial strains. Microb. Drug resist. 2012: 18(2); 137-148.

8. Javed H, Erum S, Tabassum S, Ameen F. An overview on medicinal importance of Thymus Vulgaris. Asian J. Scientific Res. 2013: 3(10); 974982.

9. Yuan H, Ma Q, Ye L, Piao G. The Traditional Medicine and Modern Medicine from Natural Products. Molecules. 2016: 21; 559-577.

10. Giordani R, Regli P, Kaloustian J, Portugal H. Potentation of antifungal activity of amphoteracin $\mathrm{B}$ by essential oil from Cinnamonium cassia. Phytother. Res. 2006: 20; 58-61.

11. Lis-Balchin M, Deans S, Hart S. Bioactive Geranium oils from different commercial sources. J. Essent. Oil Res. 2007: 8; 281-290.

12. Rosato A, Vitali C, De Laurentis N, Armenise D, Milillo MA. Antibacterial effect of some essential oils administered alone or in combination with norfloxacin. Phytomedicine, 2007: 14; 727-732.

13. Shin S, Kim J, J. In vitro inhibitory activities of essential oils from two Korean Thymus species against antibiotic-resistant pathogens. Arch. Pharm. Res. 2005: 28; 897-901.

14. Sbhatu DB, Abraha HB. Preliminary Antimicrobial Profile of Solanum incanum L.: A Common Medicinal Plant. Evidence-Based Complementary and Alternative Medicine. 2020: 2020;1-6.

15. Soxhlet F. Die gewichtsanalytische Bestimmung des Milchfettes. Dinglers Polytechnisches J. 1879. 232: 461-465.
16. Polk DB, Peek RM. Helicobacter pylori: gastric cancer and beyond. Nat Rev Cancer. 2010. 10(6):403-14.

17. Malfertheiner P, Megraud F, O'Morain CA, Atherton J, Axon AT, Bazzoli F, Gensini GF, Gisbert JP, Graham D.Y, Rokkas T, El-Omar EM, Kuipers EJ. European Helicobacter Study Group. Gut. 2012. 61(5):646-64.

18. Bronsdon MA, Goodwin CS, Sly LI, Chilvers T, Schoenknecht FD. Helicobacter nemestrinae sp. nov, a spiral bacterium found in the stomach of a pigtailed macaque (Macaca nemestrina). Int J Syst Bacteriol.1991 10.1099/00207713-41-1-148.

19. Smith SM, O'Morain C, McNamara D. Antimicrobial susceptibility testing for Helicobacter pylori in times of increasing antibiotic resistance. World J. Gastroenterol. 2014. 20(29): 9912-9921. doi: 10.3748/wjg.v20.i29.9912.

20. Mégraud, F. H pylori antibiotic resistance: prevalence, importance, and advances in testing. Gut. 2004. 53(9): 1374-1384. doi: 10.1136/gut.2003.022111.

21. Chey WD, Wong BC. American College of Gastroenterology guideline on the management of Helicobacter pylori infection. Am. J. Gastroenterol. 2007: 102; 1808-1825.

22. Vazirzadeh J, Falahi J, Moghim S, Narimani T, Rafiei R, Karbasizadeh V. Molecular Assessment of Resistance to Clarithromycin in Helicobacter pylori Strains Isolated from Patients with Dyspepsia by Fluorescent In Situ Hybridization in the Center of Iran. Biomed Res. Inter. 2020: 2020; 1-7. https://doi.org/10.1155/2020/2304173.

23. Muzaheed, Helicobacter pylori Oncogenicity: Mechanism, Prevention, and Risk Factors. The Sci. World J. 2020: 2020; 1-10. https://doi.org/10.1155/2020/3018326.

24. Aftab H, Miftahussurur M, Subsomwong P, Ahmed F, Khan AA, Yamaoka Y. Helicobacter pylori antibiotic susceptibility patterns in Bangladesh: Emerging levofloxacin resistance. J. Infect. Dev. Ctries. 2016: 10(3); 245-253.

25. Yakoob J, Fan X, Hu G, Li Liu L, Zhang Z. Antibiotic susceptibility of Helicobacter pylori in the Chinese population. J. Gastroenterol. Hepatol. 2001: 16; 981-985.

26. Dupont C, Kalach N, Raymond J. Helicobacter pylori and Antimicrobial Susceptibility in Children. J. Pediatr. Gastroenterol. Nutr. 2003: 36; 311-313.

27. Miftahussurur M, Yamaoka Y. Appropriate firstline regimens to combat Helicobacter pylori antibiotic resistance: an Asian perspective. Molecules. 2015: 20; 6068-6092.

28. Papastergiou V, Georgopoulos SD, Karatapanis S. Treatment of Helicobacter pylori infection: meeting 
the challenge of antimicrobial resistance. World J. Gastroenterol. 2014: 20; 9898-9911.

29. Tshibangu-Kabamba E, Yamaoka Y. Helicobacter pylori infection and antibiotic resistance from biology to clinical implications. Nature Reviews Gastroenterol. Hepatol. 2021: 1-17

30. Milani M, Ghotaslou R, Akhi MT, Nahaei MR, Hasani A, Somi MH et al. The status of antimicrobial resistance of Helicobacter pylori in Eastern Azerbaijan, Iran: comparative study according to demographics. J. Infect. Chemother. 2012: 18(6); 848-52.

31. Niv Y. H pylori recurrence after successful eradication. World J. Gastroenterol. 2008: 4(10); 1477-1478.

32. Wang YC, Huang TL. Screening of antiHelicobacter pylori herbs deriving from Taiwanese folk medicinal plants. FEMS Immunol. Med. Microbiol. 2005: 43 (2005): 295-300.

33. El-Shouny WA, Ali SS, Hegazy HM, Abd Elnabi MK, Ali A, Sun J. Syzygium aromaticum L.: Traditional herbal medicine against cagA and vacA toxin genes-producing drug resistant Helicobacter pylori. J. Trad. Complement. Med. 2019: 1-12. https://doi.org/10.1016/j.jtcme.2019.05.002.

34. Hashemi SA, Ghorbanoghli S, Manouchehri AA, Hatkehlouei MB. Pharmacological effect of Allium sativum on coagulation, blood pressure, diabetic nephropathy, neurological disorders, spermatogenesis, antibacterial effects. AIMS Agriculture and Food, 2019: 4(2); 386-398.

35. Moghadam FJ, Navidifar T, Amin M. Antibacterial Activity of Garlic (Allium sativum L.) on MultiDrug Resistant Helicobacter pylori Isolated From Gastric Biopsies. Int. J. Enteric Pathog. 2014: 2(2); e16749.

36. Saidulu Ch, Venkateshwar C, Rao SG. Preliminary phytochemical studies of medicinal plant drug: Withania Somnifera Linn. Biolife. 2014. 2(1): 306312

37. Aggarwal KK, Khanuja SPS, Ahmad A, Santha KTR, Gupta VK, Kumar S. Antimicrobial activity profiles of the two enantiomers of limonene and carvone isolated from the oils of Mentha spicata and Anethum sowa. Flav. Fragr. J. 2002: 17; 59-63. doi: 10.1002/ffj.1040.

38. Rattanachaikunsopon P, Phumkhachorn P. Diallyl sulfide content and antimicrobial activity against food-borne pathogenic bacteria of chives (Allium schoenoprasum). Bionsci. Biotechnol. Biochem. 2008: 72; 2987-2991.

39. Liu J, Mahmood, M.S, Abbas, R.Z, Dillawar, A, Nawaz, Z, Luqman, M, Abbas, A, Rehman, A, and Rafique, A. Therapeutic appraisal of ethanolic and aqueous extracts of clove (Syzygium aromaticum) and garlic (Allium sativum) as antimicrobial agent. Pak. J. Agri. Sci. 2021: 58(1); 245-251; 2021. DOI: 10.21162/PAKJAS/21.650.

http://www.pakjas.com.pk. 